\title{
Inserción Global en la Arquitectura de la Nueva Ruralidad: el Turismo y el Caótico Proceso de Modernización en el Perú
}

\author{
Global Insertion in the Architecture of the New Rurality: Tourism and the \\ Chaotic Process of Modernization in Peru
}

\author{
Inserção Global na Arquitetura da Nova Ruralidade: Turismo e Processo \\ Caótico de Modernização no Peru
}

\author{
César Castañeda Silva. \\ Arquitecto, MSc. Arquitectura, \\ Universidad Nacional de Ingeniería, Lima, Perú. \\ lecesarcas@gmail.com \\ (D) https://orcid.org/0000-0002-7953-435X
}

Recibido: mayo 15 de 2020

Aceptado: junio 14 de 2020

Publicado: junio 30 de 2020

\section{RESUMEN}

La inserción de la Globalización como sistema de homogeneización mundial, ha calado en los modos citadinos de convivencia, en desmedro de las sociedades rurales que, sin embargo, a través de procesos heterogéneos y diversos, asimilaron las condiciones tecnológicas, culturales y económicas de este encuentro, superponiéndose a sus modos auténticos y apropiados de realización valorados en el tiempo. El Perú, durante este proceso, intensifica el Turismo receptivo y asume un proceso de Modernización informal que, en el mundo rural, y, específicamente, en su Arquitectura deviene en divergencias y transformaciones que la sitúan dubitativamente entre lo tradicional, la banalidad y lo efímero.

Palabras claves: Arquitectura rural; Turismo; Modernización; auténtico; apropiado.

\begin{abstract}
The insertion of Globalization, as a world homogenization system, has penetrated the urban modes of coexistence, to the detriment of rural societies that, however, through heterogeneous and diverse processes, assimilated the technological, cultural and economic conditions of this encounter, overlapping their authentic and appropriate modes of realization valued over time. During this process, Peru intensifies receptive Tourism and assumes an informal Modernization process that, in the rural world, and specifically in its Architecture, becomes divergences and transformations that place it doubtfully between the traditional, the banal and the ephemeral.
\end{abstract}

Key words: Rural architecture; Tourism; Modernization; authentic; appropriate. 


\section{RESUMO}

A inserção da Globalização como sistema global de homogeneização penetrou nos modos urbanos de convivência, em detrimento das sociedades rurais que, no entanto, por meio de processos heterogêneos e diversos, assimilaram as condições tecnológicas, culturais e econômicas deste encontró, sobrepondo seus modos de realização autênticos e apropriados, avaliados ao longo do tempo. Durante esse processo, o Peru intensifica o turismo receptivo e assume um processo informal de Modernização que, no mundo rural, e especificamente em sua Arquitetura, se transforma em divergências e transformações que o colocam duvidosamente entre o tradicional, o banal e o efêmero.

Palavras-chave: Arquitetura rural; Turismo; Modernização; autêntico; apropriado.

\section{INTRODUCCIÓN}

La conformación de sociedades y los modos en que estas entendieron la importancia de los intercambios de conocimiento, permitió que, de manera diacrónica, la humanidad fomentara condiciones para desarrollar y difundir avances y logros en las relaciones entre "Unos" y "Otros". Este desarrollo establece diferencias, definiendo las culturas hegemónicas (dominantes) y las dependientes (menores) a través de modelos de imposición, conservación, apropiación, enajenación o eliminación, mediante conflictos entre elementos propios y ajenos (Larrain, 2017; Giménez, 2007; Taylor, 1993). En este mismo sentido, el proceso de globalización ${ }^{1}$ se manifiesta como uno de estos modelos hegemónicos de imposición, que amplifica las diferencias tecnócratas de las culturas dominantes, promoviendo la homogeneidad, pero que, contradictoriamente, ha permitido la conservación y apropiación de las culturas menores, que coexisten desde lo diverso y particular a través de conexiones y relaciones que operan de manera multiterritorial y sincrónica con el desarrollo de las tecnologías (Sassen, 2007).

No obstante, en estas condiciones de polaridad y dependencia, las culturas menores se permiten una situación de ventaja desde la apropiación,

\footnotetext{
1. Stuart Hall (2007) señala que la Globalización que se conoce desde los años noventa es otra forma de distintas globalizaciones que han existido anteriormente; Jorge Larraín (2005) hace referencia a la globalización como un proceso que empezaría con la modernidad europea del siglo XVl; Alfonso Roitman en su ponencia "Los esenios, la comunidad Qumrám y las sectas en el judaísmo" (2015) indica que la presencia de la Aldea Global se ve manifiesta desde la expansión realizada por Alejandro Magno en el siglo IV a.c. imponiendo la cultura helenística.
}

entendiendo que: "lo global no reemplaza a lo local, sino que lo local opera dentro de la lógica de lo global. La globalización no significa el fin de las diferencias culturales sino su creciente utilización" (Larraín, 2005, p.113). Esta apropiación, sin embargo, no termina por reducir los márgenes de desigualdad subsistente, a pesar de los diálogos interculturales y las dicotomías conformadas (Hall, 2003), redefiniendo la convivencia en sociedad, transformándola hacia una serie de modos que privilegian, de manera liberal, fluida y temporal, las comunicaciones virtuales, la tecnología digital, los traslados y la inmediatez, la individualidad y el placer del consumo (Baumann, 2013; Hall, 2007; Castells, 2000).

Esta tesitura acelera los procesos en búsqueda de encontrar las condiciones sobre las cuales las sociedades son consecuencia del establecimiento de la denominada modernidad como modo de alcanzar el bienestar común desde la racionalidad, el progreso y la libertad idealizada y pretendida etérea; aunque, ocasionalmente, se redefine desde lo heterogéneo, como sucede en el discurso de las identidades propias o "regionales". Diversos autores definieron el proceso de Globalización desde una Modernidad "sólida", condicionada a los metarrelatos, hacia una actual denominada "líquida" (Baumann, 2012), reinventada en lo diverso; o desde la denominada "sociedad transparente", en términos de Vattimo (1996). Para Lyotard y Derrida es un cambio de paradigma, que establece condiciones de ruptura denominada Posmodernidad; y como alternativa a lo moderno y posmoderno surgirán tres procesos transversales denominados "Transmodernidad" por Rosa María Rodríguez (2004) y Enrique Dussel (2005); "Ultramodernidad" por José Antonio Marina (2000) e "Hipermodernidad" por Lipovetsky (2008), todos 
estos desde una perspectiva humanística hacia lo ético, los principios y valores.

En todo caso, sea cual fuese el o los términos que definen y determinan las condiciones actuales de sociedad, lo cierto es que los modos de alcanzar la modernidad son alternativas heterogéneas que, pretendiendo alcanzar aquel estado de bienestar, pueden trazarse desde su libre determinación (Aguilar, 2012, p.7). Esta autonomía de elección se ve condicionada por lo global, que entiende lo citadino como el laboratorio de los procesos de modernización en desmedro de los modos rurales, que no han tenido otra opción que recluirse en la atemporalidad desde el olvido o migrar hacia las periferias de aquel laboratorio. Estas condiciones no deslegitiman a aquellas sociedades que, en tiempos actuales, no se sitúan desde lo establecido y perviven desde sus identidades o tradicionalismos, conformando comunidades o manifestando en términos de Kymlicka (1996, p.257) "identidades compartidas." Kymlicka señalaría que a partir de la unificación, dentro del respeto y lo diverso, se pueda encontrar lo común; entendiendo, entre otros, que lo territorial, la historia, la lengua o la religión son inherentes, indisociables e irrenunciables al hecho histórico y la memoria como herencia desde lo cognoscitivo, afectivo y social.

En este desarrollo, que intenta un retorno humanista, aún prevalece el acceso a lo inmediato y desechable, situado en un plano superior por sobre objetivos de bien común, evidenciando la alienación y la imitación del estereotipo globalizado de la sociedad capitalista neoliberal, el endiosamiento al entretenimiento y la parodia, que no solo son menester de lo publicitario, comercial y televisivo, sino que irrumpe en la política, la educación, el arte, los modos de convivencia y la cultura desbordándose hacia lo que Vargas Llosa señalaría como "la civilización del espectáculo".2

\section{La Vorágine del Turismo}

Las circunstancias actuales de la sociedad de "la civilización del espectáculo" han permitido al turismo situarse como una de las industrias más importantes

2. Mario Vargas Llosa en el 2012 presenta su obra "La civilización del espectáculo" de nombre similar al que realizara Guy Debord en 1967 "La Societé du Spectacle" al cual hace referencia para señalar las condiciones de crisis en las que se ha situado la sociedad, la cultura y el arte en general. El culto al entretenimiento y lo banal ha sobrepasado las condiciones del juicio crítico para situarse en un consumismo atado al placer y lo efímero. e influyentes en la era global a través del consumo y los mercados favorecidos por la tecnología de las comunicaciones y el desarrollo de los medios de transporte. Aunque se ha dado históricamente en la búsqueda de lo novedoso, el conocimiento y el aprendizaje por parte de burgueses, científicos, artistas y todo aquel que se aventure hacia lo desconocido, lo cierto es que el turismo se reinventó como alternativa de industria accesible a las masas haciendo atractivo el ocio y el entretenimiento de un ávido cliente "turista coleccionista de lugares" (Urry y Larsen, 2014) (Figura 1).

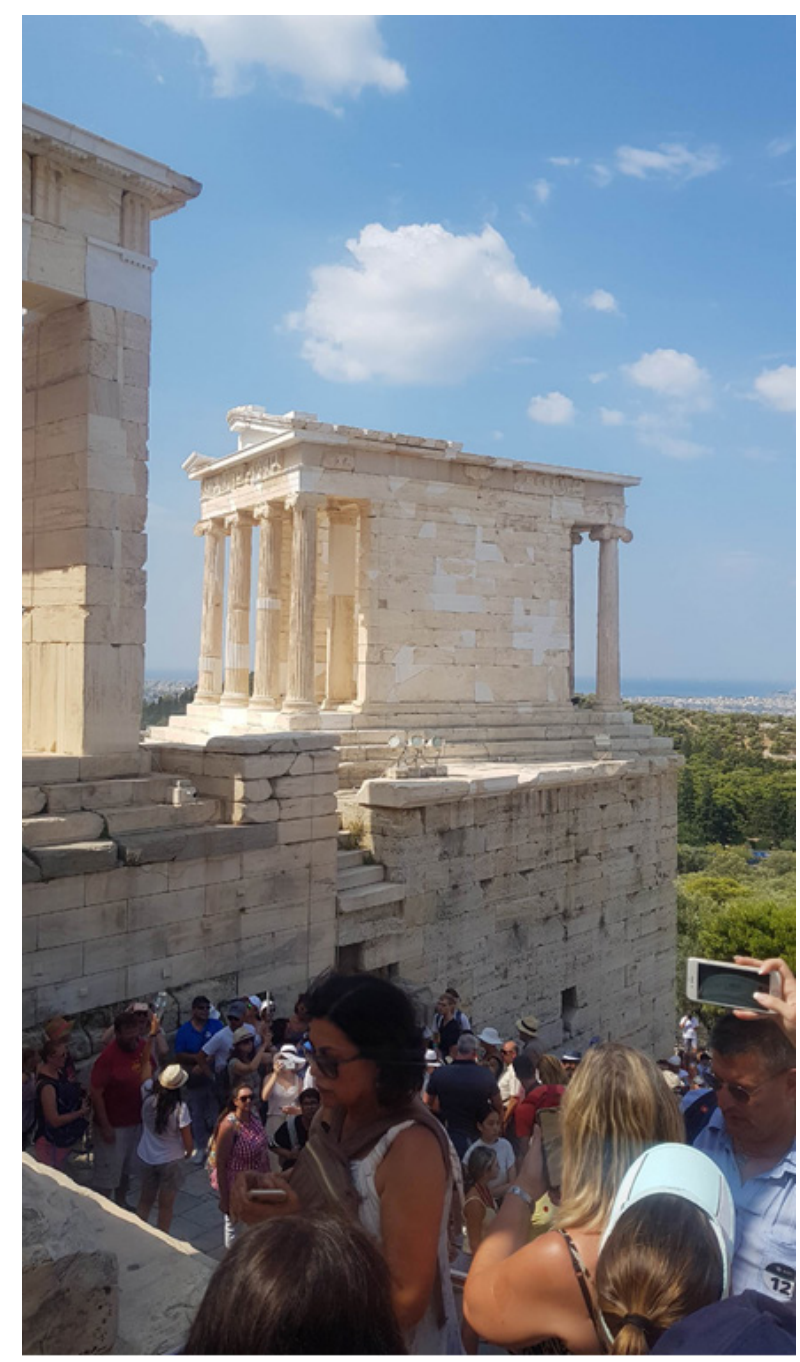

Figura 1. La Acrópolis de Atenas colapsa ante la llegada de miles de turistas "coleccionistas de lugares" que a diario ponen en riesgo los trabajos de conservación del monumento declarado Patrimonio Cultural de la Humanidad (1987). Fuente: Fotografía del autor, 2019 
La globalización permite para Urry y Larsen (2004) dos aspectos importantes; uno de ellos es que cualquier lugar del mundo puede ser potencialmente un atractor de la mirada turística, y otro que la vorágine de desplazamientos ocasionados por las condiciones de turismo, comercio, mercado y producción en general ha establecido la homogeneización de estas industrias hacia una imagen abstracta y anónima definida por Marc Augé (2000) como los "No Lugares", pero que en el camino se redireccionaría hacia el consumo de lo exótico y las particularidades.

Este modelo benévolo y lucrativo de consumo que trasmite status social, encubierto bajo la alienación, se desarrolla desde la actividad privada en el rubro hotelero, el transporte, el comercio que no repararan en el impacto ocasionado por su intromisión, generando conflictos entre el financiamiento público y privado, la propiedad local y pública, los intereses locales, privados y del Estado, así como entre la población local y la emergente industria turística regida por la rentabilidad. Se estima que el turismo mundial ha obtenido un crecimiento anual entre el 2011 y el 2015 de 4,5\%; produjo un $\mathrm{PBI}$ mundial de $10 \%$ de promedio anual desde el 2011; representa actualmente el 30\% de las exportaciones de servicios a escala mundial; así como el $6 \%$ de las exportaciones de bienes y servicios (Pentur, 2016).

Esta industria del turismo de masas, de igual manera, va al encuentro precipitado de las culturas menores, que requieren urgentemente de las instituciones del Estado para que sean catalizadoras de la administración y gestoras del entorno (ambiental, económico, socio cultural), así como de las condiciones de infraestructura que incluyan necesariamente estudios multidisciplinarios en el equilibrio entre lo masivo y el beneficio que se acarrea para la sociedad local, sin que suponga la pérdida de sus modos auténticos de convivencia (Crosby, 2009).

En América Latina. [...] la poca y mala infraestructura de servicios públicos en las áreas rurales y naturales, condiciona claramente su nivel de desarrollo. La falta de ayudas económicas y financieras y la poca capacidad de maniobra de las administraciones locales hacen que el proceso sea muy lento y demasiado atomizado (Crosby, 2009, p.32).
Un beneficio que trasciende la actividad económica constantemente se transforma en un servilismo impoluto y colonizador que ignora el significado histórico-cultural, la vulneración de la intimidad y, como señala George Yúdice (2002), la creación de una industria de proveedores y servicios de "vidas étnicas" y experiencias culturales. A esto, se suman los cambios sintomáticos del paisaje y el medio ambiente, y todo aquello que debilita las condiciones sobre las cuales se desarrollan los elementos simbólicos y los valores adquiridos de una identidad cultural. En todo caso, como señala Yúdice, se trata de reducir o eliminar la condición de "recurso" en el que se ha convertido la cultura para virar hacia su capacidad de valor auténtico.

\section{Nueva Ruralidad: la Pérdida de lo Auténtico y Apropiado}

Lo rural, como definición dada a mediados del siglo $X X$, establece una serie de conceptos que van relacionados con la naturaleza, la escasa población, la actividad agraria, la homogeneidad y la conservación de hábitos (tradiciones) como función económica y social (Gaudin, 2019; Barros, 2005; Ivars, 2000). Estos conceptos se modifican en su estructura, desde la dinámica económica de la globalización y los procesos de modernización que, al colisionar con la ruralidad, hicieron insostenible una resistencia y subsistencia destinada al aislamiento y la precariedad. No obstante, el presagio de la desaparición de los entornos rurales ${ }^{3}$, con el inicio del nuevo siglo se ha accedido a una transformación y apertura económica, social y cultural como esperanza de continuidad y vigencia, que posibilite lograr un estado de plenitud y satisfacción al poseer, alterar o rechazar lo que sea apropiado (Grimson, 2011: Subercaseaux, 2006; Villoro, 2001; Castells, 2000).

Esta categoría permite y avala a la sociedad rural apropiarse de lo que considere necesario, permitiéndole ser única y auténtica sin desentenderse de su condición y vigencia universal; "las formas

\footnotetext{
3. Desde 1950 hasta el 2000 los porcentajes de población rural decrecieron en América Latina sustancialmente desde un 59,6\% en promedio de la población total a $24.6 \%$. En 50 años países como Brasil decrecerían su población rural de $64.0 \%$ a $18,7 \%$, Colombia de $62,9 \%$ a $26,1 \%$ y Perú de $64,5 \%$ a 27,2\%. Únicamente Haití (64,5\%), Guatemala (60,3\%), El Salvador (53,7\%) y Costa Rica $(52,2 \%)$ conservarían una población mayoritariamente rural. Fuente: World Urbanization Prospects. The 1999 Revisión. New York, United Nations Population Division.
} 
del espíritu absoluto, para seguir empleando la terminología de Hegel, son en primer lugar universales y solo, luego, y si cabe se puede distinguir en ellas rasgos nacionales y no a la inversa" (Sobrevilla, 1973, p.65). Lo auténtico, como condiciones de diálogo intercultural, debería posibilitar a los modelos rurales salir favorecida detectando modos encubiertos de dominación y obviando las resistencias (Touraine,1997) sin alterar los conceptos de pertenencia, permanencia, espacio y reconocimiento, sobre los cuales se desarrollan, establecen, replantean y transmiten las identidades culturales (Larrain, 2017; Castañeda, 2013; Subercaseaux, 2006; Castells, 2001) (Figura 2).

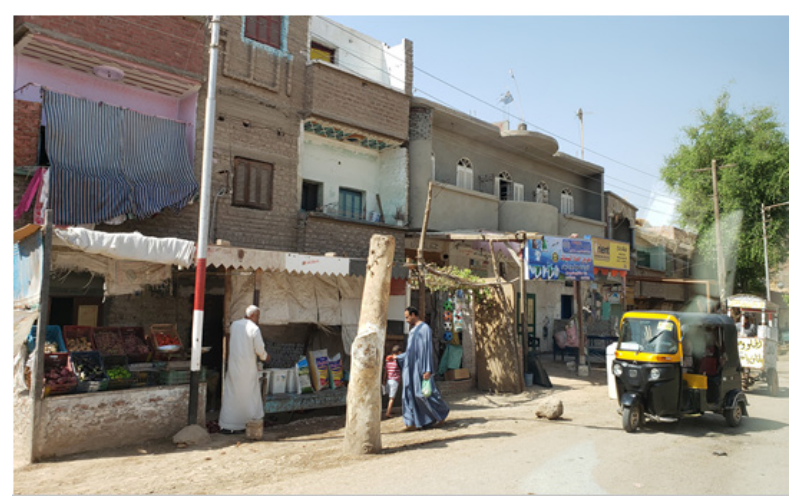

Figura 2. Poblados rurales alrededor del Templo de Abidos al sur de Egipto se adecuan a nuevas formas de subsistencia con base en el turismo, intentando no perder su autenticidad. Fuente: Fotografía del autor, 2018.

Obviamente, la búsqueda de la autenticidad, como respuesta a una apertura a las influencias, no debe confundirse con la búsqueda de la genuinidad o peculiaridad que revierta y retorne a modelos premodernos o atemporales; sino, más bien, lograrse "cuando está dirigida por proyectos que responden a necesidades y deseos colectivos básicos y cuando expresa creencias, valoraciones y anhelos que comparten los miembros de esa cultura" (Villoro, 2001, p.143). Estas expresiones quedan restringidas cuando no se otorgan las oportunidades o las condiciones de un sistema adecuado de conocimiento, reflexión y práctica de lo auténtico y apropiado al mundo rural, establecidos desde la atemporalidad, no como respuesta al diálogo intercultural sino como consecuencia del abandono que le restringiría la oportunidad de lograr el reconocimiento de la diferencia, que es desde donde se sitúa, en términos de Leopoldo Zea, el espíritu crítico de una sociedad.
Era menester adoptar, no ya los frutos de la cultura que nos servía de modelo, sino el espíritu que la había hecho posible. Imitar, no un determinado sistema filosófico, sino el espíritu que lo había realizado. ¿Cuál era este espíritu? El espíritu crítico, diríamos en nuestros días, propio de todos los hombres y pueblos. La capacidad para seleccionar, en función con el propio modo de ser, sin cuestionarlo. (Zea, 1974, p.33).

Sin embargo, estas condiciones idóneas de autenticidad y apropiación con las que se deberían lograr un abordaje y la reestructuración del área rural, no son tomadas en cuenta en el encuentro con lo globalizado, favoreciendo factores de homogeneización en el acercamiento ruralurbano, procesos de retorno, expansión de medios de comunicación, adaptación de usos y hábitos urbanos, nuevas viviendas de ricos y el turismo de masas que han determinado conceptos como lo rururbano (Arango, 2008; Barros, 2005) o la nueva ruralidad (Gaudin, 2019; Claverias, 2008; Ivars, 2000).

La nueva ruralidad supone un proyecto colectivo, apropiado, entendiendo las transformaciones sociales, políticos y culturales globales, sin dejar que se preserve lo rural a partir de lo sostenible, sustentable, el reciclaje, lo renovable, los sistemas limpios de energía y la conservación ecológica que, en el ámbito rural, se lleva inscrito en la continuidad de sus tradiciones y modelos simbólicos, así como en la incorporación de la flora, la fauna y el territorio como paisajes vivos, quedando abierta la posibilidad de que, en ocasiones, apartarse del sistema establecido sea lo apropiado en la conservación de elementos simbólicos tangibles y emocionales que constituyen su identidad cultural.

En este proyecto colectivo se debe actuar desde una serie de competencias económicas, sociales, culturales, ambientales y políticas (Arango, 2008; Claverias, 2008) desde la autonomía, la autosuficiencia, la diversificación y la gestión, que aún se obstaculizan por lo acelerado del proceso global, así como por limitaciones conocidas como: " la regresión demográfica, carencia de población activa cualificada, incapacidad financiera y técnica, presiones económicas y sociales exógenas, desmoronamiento de actividades económicas tradicionales, etc." (Ivars, 2000, p.72). Este mismo proceso, debe evidenciar sus diversas influencias culturales que, en el tiempo, a través de un 
proceso de decantación, se vuelve conformador de sus modelos vernaculares, tal y como sucede con la Arquitectura, que de manera espontánea y experimental es expresión racional, espiritual y de goce estético en el ser humano ${ }^{4}$.

[...] la nueva ruralidad es un concepto que va más allá de la pluriactividad o las labores no agropecuarias en el medio rural. La "nueva ruralidad" es el contenido utópico del cambio propiciado por las comunidades y actores rurales. El enfoque de la nueva ruralidad, por lo tanto, es otro factor que ayuda a construir el concepto de desarrollo territorial, donde las ciudades intermedias y los corredores económicos juegan roles imprescindibles para esta integración de la nueva ruralidad, con las posibilidades que la gente del campo tenga una vida mejor (Claverías, 2008, p.38).

Lo rural, como proyecto colectivo, contiene dimensiones propias que permiten múltiples relaciones vivenciales en su relación sociedadterritorio-cosmovisión, y que puede entenderse, entre otras manifestaciones, en la vivienda y el espacio público. Aquí, los límites de privacidad entre ellos se pierden, para ser conformadoras de una sola entidad con distintas cualidades espaciales; del mismo modo, la apropiación de la calle o el paisaje natural se sitúa como ampliación (terraza) de la vivienda, dándose sentidos de sociabilidad, pertenencia y reconocimiento. El espacio público constantemente propone límites, bajo patrones de apropiación perceptual que trasciende lo físico hacia múltiples direcciones condicionadas por su cosmovisión y el territorio que le otorgan permanencia, y que, en algunas ocasiones, se extiende sobre los límites de la perspectiva visual. No se deja de lado la exploración que entiende al espacio público, sin una inicial intervención humana apropiándose espontáneamente del paisaje, desarrollando vínculos polifuncionales y al cual se le ha dado reconocimiento, pertenencia y condiciones simbólicas.

La vivienda y el espacio público rural conservan

\footnotetext{
4. "Los códigos estéticos pertenecen a la experiencia subjetiva, íntima y afectiva que tiene cada hombre ante la realidad. El término estético, en su sentido más amplio, designa la facultad de percibir, sentir y no se refiere solamente a lo bello, sino también a lo sensible, a lo intuitivo, a lo contemplativo y a todo aquello a lo que va ligado a las posibilidades que tiene un sujeto de experimentar emociones, cuando la realidad exterior o interior le provocan un fuerte impacto en el espíritu" (Palau, 2002, p.89).
}

tradiciones y vínculos que se trasmiten desde la memoria colectiva (Gutiérrez, 1997; Waisman, 1993) hacia el modo presente, a través de significados y representaciones de los eventos, sucesos y fenómenos naturales, como parte de la belleza y el goce estético que conforman las experiencias sensoriales y existenciales, condición inalterable de sus cosmovisiones, que necesitan ser aprendidas y (re) aprehendidas para convertirse en energía y experiencia, algunas veces antropizado y otras en estado virginal, que es sincrónicamente sujeto vivo, simbólico y presencial, comunicación y equilibrio (Borja, 2016, p.80). Todas estas dimensiones son definidas por Perniola (2016) como horizonte estético; es decir la confluencia de lo bello, el arte, la filosofía (cosmovisión) y el estilo de vida ejemplar (ruralidad) que permiten encuentros constantes entre el sentido de la vida, la ética y lo artístico (Perniola, 2001).

Lastimosamente, estas dimensiones colapsan dando paso a un nuevo paradigma rural que tiende aceleradamente a incorporar las perversiones del consumismo, la globalización y los modos urbanos de modernización desde la alienación y la banalidad (Gaudin, 2019). El espacio público y la vivienda dejaron de ser el sujeto vivo, simbólico y presencial, reducidos a objeto de complacencia de experiencias caprichosas arbitrarias (Perniola, 2001) del turista coleccionista de lugares y de los vicios que acarrea los modelos de construcción urbana periférica, que irrumpe, degrada y depreda.

\section{Perú: el Proceso de Modernización y el Turismo Rural}

El inicio de inserción latinoamericana al entorno global, coincidirá en el Perú con la crisis socio económica más profunda de su historia republicana, sumido en una guerra interna con el terrorismo, la hiperinflación, la desaparición de la clase media, el aumento de la condición de pobreza, la marginación del Estado peruano de las instituciones financieras internacionales y el olvido de lo rural que, de representar poblacionalmente el 60.1\% (1972), se redujo abruptamente a $20,7 \%$ (2017), como consecuencia de la desbordante migración hacia la capital (Lima), que pasó de tener, en 1940, 645,172 habitantes; en 1993, 6'321,173 habitantes; y, al 2017, 9'485,405 habitantes. Las drásticas medidas económicas dictadas por Alberto Fujimori durante su primer gobierno (1990-1995), permitiría lograr la reconstrucción nacional, posibilitando que los 
gobiernos siguientes sostengan un crecimiento continuo y uno de los más importantes en la región. ${ }^{5}$ Este crecimiento, sin embargo, no solo se debía al sistema neoliberal establecido, sino también a la actividad económica paralela informal, realizada por los millones de migrantes que hicieron del comercio, los servicios y la mano de obra un modo de subsistencia, que construiría y constituiría la nueva clase media peruana.

Denominada la clase "emergente", los migrantes inicialmente tuvieron que lidiar con el racismo y la discriminación por parte de los limeños, que veían en sus costumbres y tradiciones, trasladadas del campo a la ciudad, modos premodernos en un proceso complejo de hibridaciones y sincretismos culturales durante los años setenta y ochenta. El nuevo ámbito citadino les permitiría apropiarse de aquellos medios tecnológicos e industrializados desconocidos en el ámbito rural, situándolos en la dicotomía de definirse como moderno o continuar como provincialista. Este choque encuentra sus primeros modos de apropiación desde la música denominada despectivamente "chicha"; apelativo que más adelante en su adopción y aceptación incluiría al comercio ambulatorio; los ámbitos artísticos, festivos y publicitarios; el desorden y una estética particular donde abundan los excesos, lo caótico y un mal gusto denominándoseles como conjunto, la "cultura chicha". 6 Una cultura intensificada durante los años noventa, que el proceso neoliberal

5. Miriam Chion (2002) indica que la producción nacional se incrementó en un 43\% entre 1992 y 1998; entre 1990 y 1994 la tasa de inflación anual declinó de $7600 \%$ al $20 \%$ y entre 1990 y 1997 las exportaciones se duplicaron, las importaciones se triplicaron y la inversión extranjera se cuadruplicó. Entre 2001 y 2006 la economía creció $4.8 \%$ como promedio anual; $6.9 \%$ durante el período 2006-2011; mientras que en el período 20112016 se logró un crecimiento de 4.2\% en plena desaceleración económica mundial.

6. El término "Chicha" en el Perú se hace recurrente en los años ochenta para designar la fusión musical realizada por la población migrante en Lima entre el huayno del ande, el rock de la capital y la cumbia colombiana escuchada en la costa norte que en sus inicios sería resistida y marginada por parte de la sociedad limeña. "Los Shapis", "Chacalón" y "Los Demonios del Mantaro" serán los principales exponentes de este ritmo que como término fue autodenominado por "Los Shapis" referenciando un brebaje ancestral que permita diferenciarse de la cumbia colombiana. En la década de los noventa lo "chicha" superó la designación musical (ya difundida por Latinoamérica) para representar las costumbres artísticas y culturales de los propios migrantes y ampliado a la vida cotidiana, la informalidad y el mal gusto. Finalmente, desde el inicio del siglo XXI con una población migrante establecida en todos los estratos socio- económicos del país, la reinventada "cultura chicha" difunde su música artisticidad y cultura mostrándose como un nuevo referente identitario que el Estado difunde durante el boom del turismo. y su masificación le permite ser oficializada por la sociedad peruana y que evidenciará, sin embargo, que no todo lo "chicha" deviene en mal gusto o grotesco, sino que también producirá logros como lo expresado en la música y la grafía popular (Ludeña, 2013, p.162) (Figura 3)

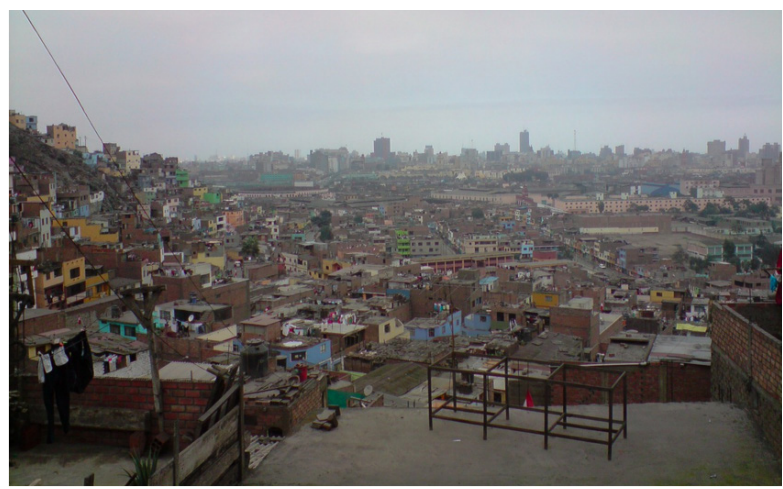

Figura 3. Viviendas en el Cerro San Cristóbal, próximas al Centro Histórico de Lima. Crecimiento informal y tugurizado como características de la modernización informal "chicha". Fuente: Fotografía del autor, 2013

Los estudios de José Matos Mar (1984), Hernando de Soto (1986), Carlos Franco (1991, 2014), Carlos Degregori (2000) y José Ignacio López Soria (2007, 2005 , 2001), señalarían este proceso como una original transformación social desde la carencia, lo espontáneo y a espaldas del Estado, denominada "modernidad alterna" o la "otra modernidad", producida paralelamente a la desarrollada como modernidad neoliberal.

[...] la modernidad que en el Perú no se supo entender o vislumbrar es la que crecía en los suburbios de la sociedad como otra forma de modernidad, dos modernidades, una en emergencia y otra efectuada por la burguesía intelectual, expresaban una modernidad del tipo burguesa, pero al mismo tiempo se estaba expresando la otra modernidad, una modernidad popular que es la que vemos y vivimos hoy. (López Soria en conversación personal, 2012).

Ambos proyectos estarían más cercanos a una modernización sin modernidad, priorizándose la forma y no el contenido. "El 'proyecto nacional' contemporáneo se encuentra recreando procesos de modernización infraestructurales, de consumo, de acceso a servicios básicos, y algunos programas sociales de carácter populista; es decir, modernizaciones de forma más que de fondo" 
(Aguilar, 2012, p.21). En este aspecto, el proceso de modernización popular, desde lo cultural, tendría desencuentros entre el bienestar y el valor producido, y las condiciones de ilegalidad, desorden e informalidad como ejecución, que se fomentaría como parte de un modelo entendido como acultural, inesperado e inaceptable como resultado por la sociedad política, académica y aristocrática, que terminarán finalmente escabullidos dentro del sistema y donde lo rural nunca estuvo considerado.

Condiciones paralelas y antagónicas entre lo informal y lo caótico como ejecución y las mejoras económicas y de imagen de país permitirán entender como consecuencia tanto al modelo "chicha" como a la vorágine del turismo. En estas condiciones de un país fortalecido en el reconocimiento de "Unos" y "Otros", tres recursos turísticos serán los de mayor interés que irónicamente convergerán en el mundo rural. El primero de ellos, desde la importancia adquirida por el patrimonio cultural arqueológico prehispánico; el segundo, por la amplitud y diversidad ecológica y medioambiental; y, finalmente, por la diversidad y calidad de la gastronomía que apertura y amplía el turismo receptivo?.

Hasta aquí, poco o nada que señalar de un intento de modernización del ámbito rural destinado a la reducción de una población aislada y premoderna que, no obstante presagiarse su desaparición, pudo resguardar vínculos, tradiciones y cosmovisiones, como legado de resistencia y subsistencia, en algunos casos como decisión, pero, principalmente, como única opción en salvaguarda del patrimonio cultural y natural como condición inherente, indisociable e irrenunciable al hecho histórico y la memoria desde lo cognoscitivo, afectivo y social. Este proceso, en lo socio-cultural, devendría en la evanescencia de los modos auténticos de ruralidad, engullidos por una modernización propia de las realizadas por lo

7. El flujo de turistas internacionales tuvo un crecimiento constante ingresando en 1998 (735,000 turistas), en el 2008 $\left(2^{\prime} 057,620\right)$ y en el $2018\left(4^{\prime} 400,000\right)$. De igual modo se verifica en el crecimiento del flujo turístico en la permanencia promedio de arribo de los huéspedes que en el 2006 era de $26^{\prime} 713,959$ (22'494,855 nacionales, 4'219,104 extranjeros) y el 2016 fue de 51493302 (43'534,380 nacionales, 7'958,922 extranjeros). Fuente: https://www.inei.gob.pe/media/MenuRecursivo/publicaciones_ digitales/Est/Lib1483/cap22/cap22.pdf

El Perú en el índice de competitividad de viajes y turismo a nivel mundial figura en el puesto 12 (recursos naturales) y puesto 26 (recursos culturales y viajes de negocio); de igual manera se manifiestan las deficiencias de un turismo aun precario e informal situándolo en el puesto 102 (sostenibilidad ambiental), puesto 117 (seguridad) y puesto 118 (infraestructura del transporte terrestre y portuario). Pentur (2016). popular urbano, institucionalizando lo "chicha" desde la informalidad, lo ilegal, una supuesta artisticidad y la añorada modernización que atentan aceleradamente contra la vivencialidad rural.

[...] a pesar del patrón y modelo de desarrollo excluyente, que perpetuó las formas tradicionales deorganizar la sociedadyel poder(modernización sin modernidad), se encuentra que las sociedades rurales y las economías campesinas han tendido a la apertura de sus relaciones sociales, a la búsqueda de nuevos caminos económicos de vida, a la autoafirmación, a desarrollar la capacidad de interactuar en distintos contextos ,de innovar y adaptar la tecnología y de funcionar en economía abierta, sin mayor aporte institucional, es decir, son portadoras de modernidad sin modernización en el medio rural (Plaza, 1998, p.122-123).

Estas condiciones rurales -a las cuales solo debieron añadirse los aportes globales desde los avances en las comunicaciones y los medios de transporte, la agro-industria, las condiciones de sostenibilidad, el desarrollo rural de su crecimiento demográfico, el énfasis en las energías renovables, la problemática de la vivienda, la salud y la educación - serán, por parte del Estado, condiciones extremadamente tardías y reducidas como acoplamiento a los intereses globales, no estableciéndose como prioritarias en el proceso de la nueva ruralidad. Bajo estas aserciones deberá permitirse que las condiciones locales que para sus pobladores, generación tras generación, se cultivó como memoria cultural y legado sempiterno, pueda sostenerse desde su institucionalidad ante una inminente continuidad de la modernidad sin modernización que se vuelve etérea, temiendo por su letargo y extinción en un devenir hacia el uso de la cultura como recurso y como espectáculo.

\section{Divergencias en la Arquitectura Nueva Rural Peruana}

La revaloración de las condiciones rurales en su relación con la Arquitectura, adquirirá interés desde los particularismos que se instalan en el proceso global como escape a los metarrelatos y a pesar de no ser un tema inédito, como lo señalarían Keneth Frampton (2000),William Curtis (2007) o desde los Seminarios de Arquitectura Latinoamericana (19852015), lo vernacular ha tenido un nuevo amanecer conflictivo desde modelos que no precisamente van en favor del resguardo de la geografía, la 
cultura, la memoria colectiva y su realización como manifestación identitaria.

Hacer arquitectura. [...] implica buscar - y ojalá encontrar- la confluencia entre geografía e historia. [...] De la historia, por muy incipiente que sea, queda una lección para conocer, interpretar y mantener una memoria sobre lo que ya se hizo y perdura. De la geografía -en estas regiones majestuosas e indómitas- quedan no solo enseñanzas sino motivaciones que permiten enriquecer la espacialidad (Rogelio Salmona en el discurso de aceptación del premio Medalla Alvar Aalto, como se cita en Ramirez, 2013, p.41).

En este proceso, la arquitectura realizada en el ámbito rural peruano será consecuencia exclusiva de las condiciones sociales, políticas y económicas en las que estuvo sumido el Estado. Un primer momento de crisis migracional, permitió que el reducido número de pobladores que permanecieron en sus pueblos, evitaran su colapso en la salvaguarda de los mitos, tradiciones y modos de convivencia. La arquitectura vernacular, como referente auténtico, continuó las maneras experimentales de acondicionamiento territorial a través de distintas tipologías, fiel consecuencia de las condiciones geográficas y climáticas, de las necesidades de hábitat, sociabilización y confort, así como de los procesos de intercambio cultural que permitieron influencias por apropiación, imitación o imposición, que luego decantaron espontáneamente y se adaptaron, permitiendo en conjunto una identidad cultural $^{8}$ (Figura 4.)

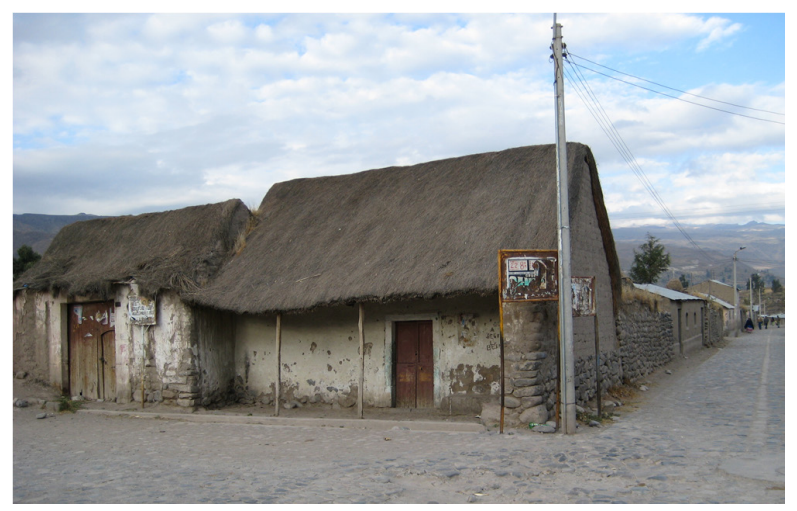

Figura 4. Distrito de Yanque, Arequipa. Ubicado a 3400 msnm. Arquitectura tradicional en piedra, adobe e ichu que permiten mantener sus condicionantes vernaculares.

Fuente: Fotografía del autor, 2014.

8. Jorge Burga en "Arquitectura Vernácula Peruana. Un análisis tipológico" (2010) realiza una importante descripción y análisis de las diversas tipologías vernaculares encontradas en el Perú.
Más allá de las estoicas condiciones sobre las cuales se refugian las tradiciones y la memoria, lo cierto es que la realización de la arquitectura vernácula no termina por cubrir las necesidades de habitabilidad, sea por las condiciones extremas del clima, la actividad sísmica y la carencia de servicios básicos (agua y alcantarillado, luz, gas natural, infraestructura de transporte público y telecomunicaciones) que señalan el estado de precariedad y riesgo encontrado. ${ }^{9}$

Un segundo momento, de reajuste neoliberal, el empoderamiento de una cultura "chicha" y la vorágine del turismo receptivo, condicionará la arquitectura rural a mostrarse en una doble problemática. La primera, desde la expansión acelerada de la cultura "chicha" en el encuentro rururbano, que transgrede lo rural mediante una acelerada modernización informal o de hibridación (Burga; 2013,2010). La segunda, desde la frívola relación con el boom del turismo, a partir de una apertura global realizada sobre los espacios públicos y las edificaciones como extensión del folclorismo promovido por la industria turística, el honramiento ensimismado de autoridades, la alienación y la aculturación (Ludeña, 2013). En ambos modelos, no se evidencia la perspectiva humanística planteada como respuesta a los procesos globales.

Lo que se advierte inicialmente, es la pérdida de los valores que manifiesta la arquitectura vernacular, como determinante y componente de una identidad cultural amenazada por la nueva ruralidad que

9. El terremoto del 15 agosto del 2007 de magnitud 7,9 en la escala de Richter, dañó severamente el departamento de Ica. Según el informe "Estudio de reconstrucción con viviendas sismorresistentes en la República del Perú" (2009), de las 90,682 viviendas de tipo vernacular en adobe y quincha $(73.5 \%$ del total de viviendas) 56,213 fueron destruidas y 28,643 quedaron inhabitables. El informe señala que el plan de reconstrucción fue mal gestionado promoviéndose la autoconstrucción de viviendas en concreto y ladrillo, verificándose condiciones precarias de enseñanza sobre adobe reforzado, una mala información y difusión que incide en el alto porcentaje de habitantes que relacionan el adobe como estructura no acorde frente a eventos sísmicos. El informe no evidencia relación alguna con los procesos culturales e identitarios desde la vernacularidad como parte del proceso.

El Informe "Evaluación de Impacto de la primera fase de "Mi Abrigo". Línea de base." (2017); permite verificar que recién a partir del año 2012 el problema del friaje en áreas rurales se volvió un Plan Multisectorial del Estado y desde el año 2008 recién el Ministerio de Vivienda implementaría la tecnología de muros trombe; anteriormente en el 2007, el Banco Mundial había recomendado al Estado invertir en el sistema de cocinas mejoradas. Una serie de propuestas como las señaladas verifican la inacción del Estado para lograr objetivos primordiales entre ellos los de salud. 
la engulle desde la informalidad, el aumento demográfico y el avance de la industria del turismo, que incorpora tipologías novedosas de servicios, comercios, actividad nocturna, ocio, entre otros, mutando hacia un repertorio arquitectónico de producción industrial e imagen figurativa-simbólica.

Esta pérdida de valores en una informal nueva ruralidad, actúa únicamente sobre las competencias económicas, dejándose de lado las sociales, culturales, ambientales y las políticas, no logrando el proyecto colectivo de la autonomía, autosuficiencia, la diversificación y la gestión, que son trasladadas a la arquitectura tendiendo hacia una homogeneización de las tipologías urbanas "chicha", realizadas sin la participación de profesionales, con crecimientos tugurizados, apropiaciones ilícitas de lo público y gustos particulares en el exceso de formas, alienaciones y copias insólitas (Burga, 2013; Tokeshi, 1999,2004).

La homogeneización se verá mayormente reflejada en las tipologías constructiva, funcional, espacial y formal, así como en la imagen proyectada. En ese sentido, la tipología constructiva se afirma sobre el uso de materiales industriales (cemento, acero, vidrio, fierro, concreto, aluminio, cerámico, fluorescentes, etc.), reemplazando los materiales tradicionales de la costa (la caña, el horcón, el algarrobo, la quincha, el barro), la sierra (la piedra, el adobe, la quincha) y la selva (madera, hoja de palma); en algunos casos se permite una combinación de ambos, pero donde predomina lo industrial, que incorporaría además calaminas, fibrocemento y esteras. La tipología funcional incluirá áreas destinadas a nuevos usos y la desaparición de otros (vinculados al paisaje exterior y la labor del campo); de igual modo, se incorporan escaleras expuestas a la calle y la utilización de la mayor cantidad de área techada posible en desmedro de la iluminación natural, la ganancia de calor y/o ventilación natural que, como condicionantes tradicionales del confort térmico, quedan relegadas. La tipología espacial va a reflejar la flexibilidad de los nuevos materiales industriales y la estandarización de medidas en los niveles de altura, vanos, carpinterías y recintos interiores; se dejan de lado condiciones espaciales propias de las diferentes regiones en su vínculo interior-exterior, a través de elementos virtuales construidos con caña en la costa o sierra, y hoja de palma en la selva, que ahora se reemplazan por espacios destinados para automóviles y maquinarias con cercos enrejados de protección o tomando la vía pública, pero, principalmente por la primacía del valor del metro cuadrado de terreno. La tipología formal, casi siempre como respuesta al clima (alargadas y fragmentadas en los lugares de calor, compactas en los lugares fríos, con pendiente en los techos para las precipitaciones, la inclusión de aleros para la sombra, etc.) es obviada para establecer una homogeneización imitativa del proceso de vivienda "chicha" realizada por etapas e inconclusas en distintos niveles, bajo la misma distribución.

Todas estas alteraciones llevan al olvido la imagen bucólica y nostálgica percibida como parte del propio entorno natural, que le dotaba a lo rural desde la horizontalidad, homogeneidad, simpleza y vínculos con el territorio, de carácter y belleza particular, que se extravían con la inserción de una nueva imagen impostada, citadina popular y de crecimiento vertical en la nueva ruralidad. Arte, estética y valor se confunden constantemente entre la serie de experiencias sostenidas en el vínculo de lo antropizado y lo natural dándose un particular canon de interpretación. (Figuras 5,6,7 y 8).

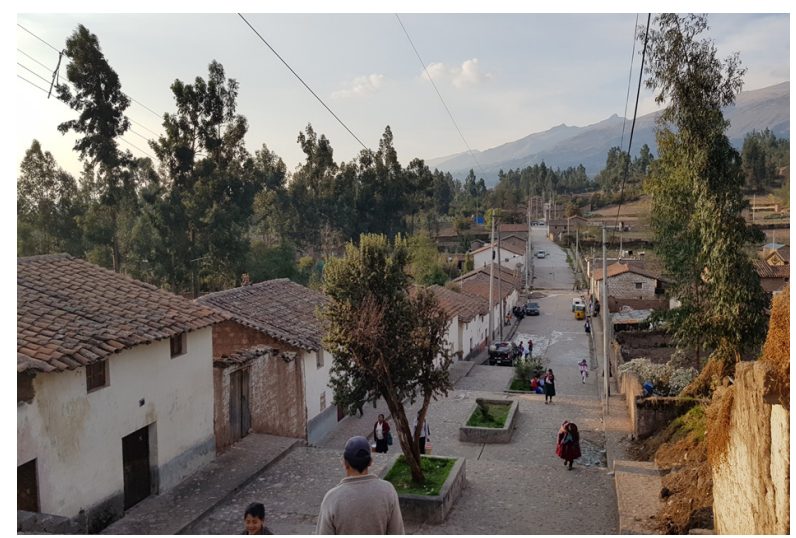

Figura 5. Distrito de Quinua, Ayacucho. Ubicado a 3275 msnm. Conservación del ámbito rural expresado en su espacio público, el paisaje y las viviendas vernaculares.

Fuente: Fotografía del autor, 2017.

Estas alteraciones producidas para autores como Jorge Burga o Juan Tokeshi, son procesos normales que, históricamente, se han dado en la arquitectura rural, teniendo como antecedentes a las influencias recibidas en la Colonia y la República (arquerías, balcones de madera abiertos y cerrados, la planificación urbana a modo de damero, las portadas características de iglesias, conventos y palacios), hoy en día consideradas vernaculares, haciendo legítimo el proceso actual de influencia "chicha". 


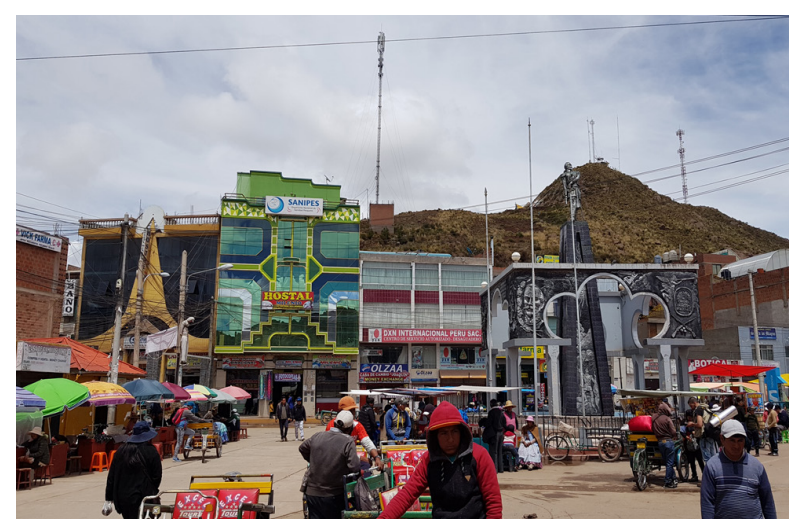

Figura 6. Distrito de Desaguadero, Puno. Ubicado a 3800 msnm. Irrupción de la cultura "chicha" en reemplazo del otrora ámbito rural expresado en su espacio público y los novedosos edificios que la rodean. Fuente: Fotografía del autor, 2018.

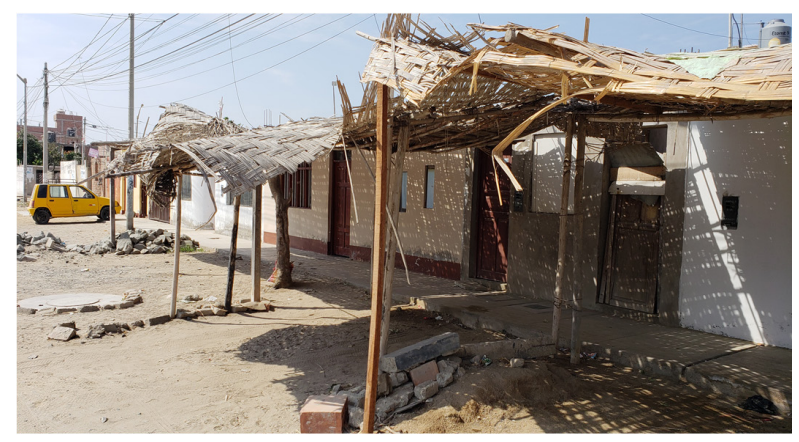

Figura 7. Distrito costeño de Nuevo Chimbote. Proceso de modernización informal. Las viviendas de adobe van dando paso a la estructura de ladrillo, los antiguos espacios semitechados de caña en algunos casos se conservan con esteras y en otros se van reemplazando con cemento para el uso del automóvil invadiendo el área pública. Fuente: Fotografía del autor, 2019.

Estos ricos estilos no fueron producto solo de contingencias locales relacionadas con la cultura, el clima y los materiales del lugar, sino también resultado de influencias tanto cercanas como muy lejanas. Una vez establecidos los tipos, no se homogeneizaron las expresiones, en cambio se estableció un denominador común, a partir del cual se fueron produciendo las variaciones estilísticas del acervo arquitectónico vernáculo. (Burga, 2013, p.102).

Burga respalda el proceso, al recurrir como discurso a una serie de modelos que empiezan a formar parte del repertorio simbólico de las actividades locales. "en la arquitectura chicha se mezcla elementos modernizantes [...] con otros de carácter tradicional [...]. Es curioso ver cómo estas formas se replican en las decoraciones de camiones y muebles vendidos en los mercados" (Burga, 2013, p.102).

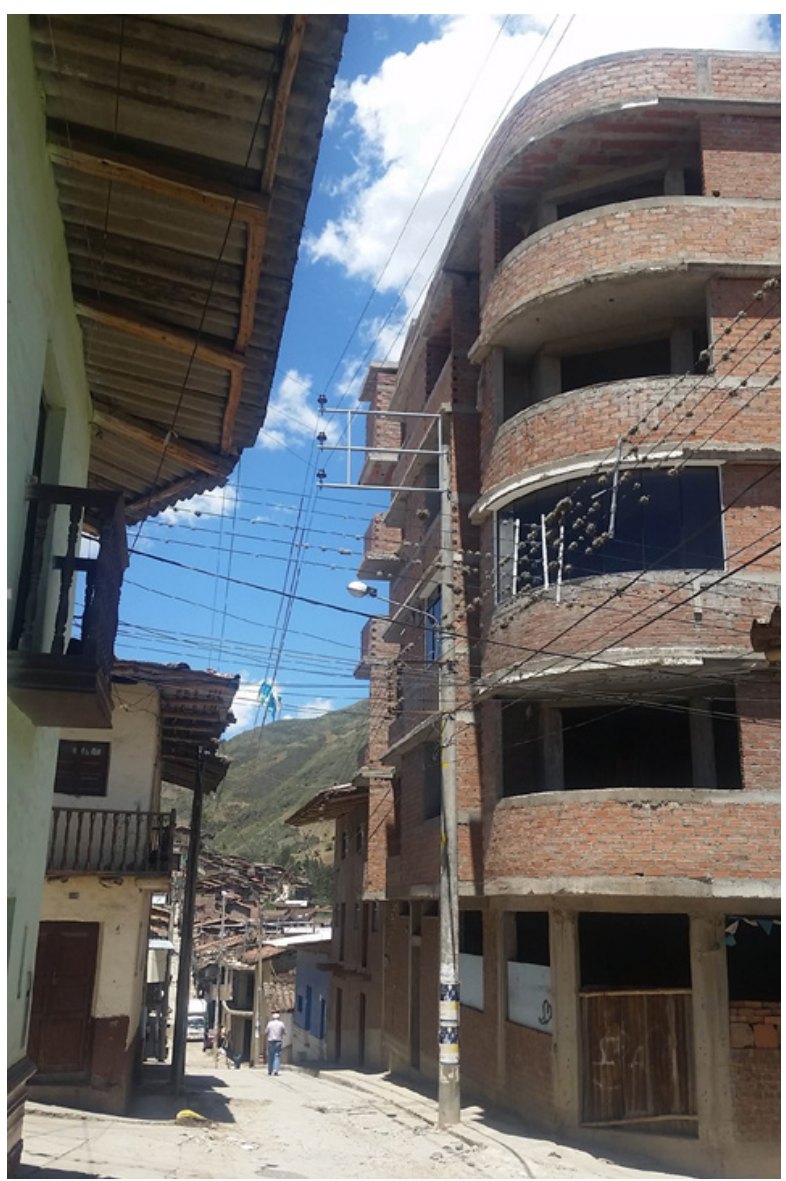

Figura 8. Distrito de Otuzco, La Libertad. Proceso de modernización informal. Las viviendas tradicionales de adobe de dos niveles se ven alteradas en su escala e imagen por construcciones informales realizadas en estructura de concreto y ladrillo, formalmente gratuitas y no siendo consecuencia de sus condiciones de hábitat y clima. Fuente: Fotografía del autor, 2015.

Esta afable objetualidad le permite avalar el repertorio de formas dispersas y anecdóticas señalando que pertenecen a distintas "modernidades" que se pueden construir en el Perú contemporáneo, donde lo "chicha" y lo vernacular son dos opciones no excluyentes de una nueva ruralidad. "Somos creyentes que debe haber un futuro que recoja lo mejor de lo vernáculo y su adecuación al clima y acondicionamiento arquitectónico, así como a los recursos del lugar y los combine con la fuerza y desenfado de la chicha, en una clave de contemporaneidad y cultura." (Burga, 2013, p.103) (Figura 9). 


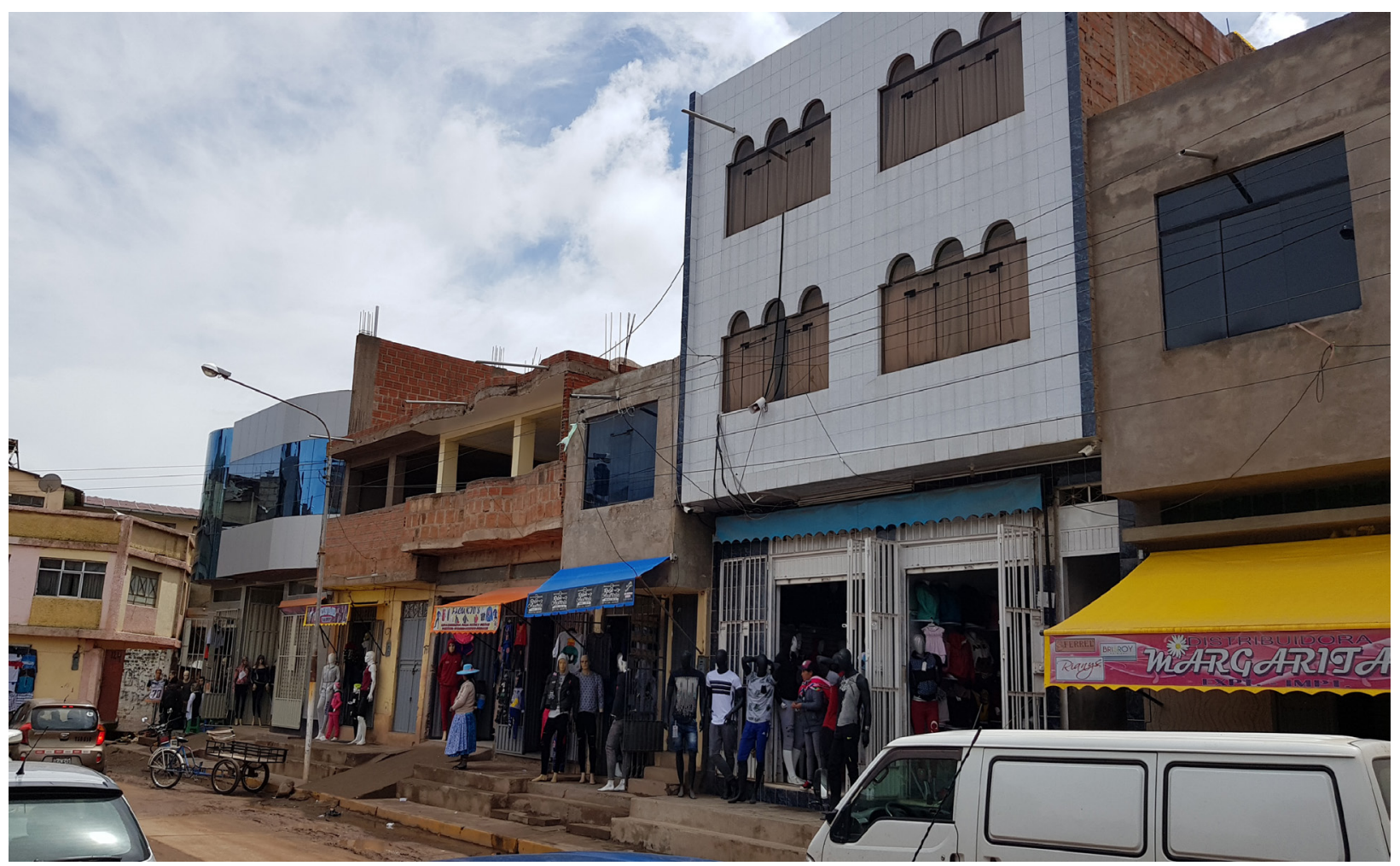

Figura 9. Distrito de Desaguadero, Puno. Diversidad de formas, texturas, enchapes y colores en propuestas basadas exclusivamente en el gusto personal e inapropiados para el frio extremo durante el invierno. Fuente: Fotografía del autor, 2018.

Las alteraciones producidas también se aprecian en los espacios y objetos públicos, donde convergen tanto la industria turística como una supuesta artisticidad o estética "chicha", mostrando versiones incongruentes con los valores artísticos, culturales, simbólicos o de relación con el paisaje. Los espacios públicos rurales olvidados y deteriorados pierden su condición de sujeto vivo, simbólico y presencial que se definen por su relación con el paisaje, la simpleza en el uso de empedrados o en otros casos dando a conocer el proceso de intercambios culturales, situando la típica plaza cuadrada con senderos, piletas y ornamentos realizados con materiales locales que definen su sincretismo. En la nueva ruralidad, los espacios públicos son reemplazados por arbitrarias tipologías destinadas a lo que denomina Yúdice (2002) como "experiencias culturales".

Ludeña (2013, p.162) encuentra cuatro particularidades en el "gusto popular" de los espacios públicos de la modernidad neoliberal e informal, verificables en esta engullición del espacio público rural. Un neonacionalismo regional, que intenta recrear discursos de identidades regionales a través de disforzados hitos simbólicos; la huachafería ${ }^{10}$ aculturada, que intenta referenciar culturas no locales y casi siempre como caricatura de temáticas limeñas o extranjeras, como anhelo de modernidad; lo chicha popular, que alude a una serie de motivos desde la figuración; y la tradición naive, que, desde lo chicha, se manifiesta ingenua, pero con sentido artesanal.

No existe duda de que la estética y ética chichas dominan el nuevo lenguaje de los espacios y monumentos públicos en las ciudades del país. Y no solo eso: este lenguaje pareciera ya haberse transformado en una especie de imagen oficial del país, a juzgar por las imágenes- símbolo que del Perú se fabrica hoy en el mundo del negocio turístico. (Ludeña, 2013, p.172).

Espacios, monumentos y objetos de irreverentes diseños y dudosa calidad artística reflejan la

10. Término empleado en el Perú para la designación de manera despectiva de elementos cursi o de mal gusto que constantemente es asociado a lo "chicha". Ludeña (2013) señala que lo huachafo es un atributo interclasista mientras que lo chicha es derivado del conflicto étnico mundo andino y urbano. 
modernización informal y aculturada "chicha", así como los motivos simbólicos y alienados de éxito celebrados por los locales y por el "turista coleccionista de lugares en la nueva ruralidad. En este vasto repertorio aparecerán motivos dedicados a la papa, al maíz, al inca, al ushnu, al puma, al Inti, al sombrero, con una serie de acabados de irreverentes diseños celebrados por los locales y por el "turista coleccionista de lugares".

Algunas de estas características pueden servalidadas en las "experiencias vivenciales" que se ofrecen en destinos como las islas flotantes de "Los Uros" o supuestos pueblos amazónicos Ashaninkas, donde la arquitectura, de manera cómplice, se convierte en escenografía de una representación teatralizada, que recrea pueblos, sociedades, costumbres y modos de convivencia con horarios establecidos y donde la mayor parte de esa población vive en la urbe, convirtiéndose exclusivamente en un objeto turístico inauténtico"11 (Figura 10).

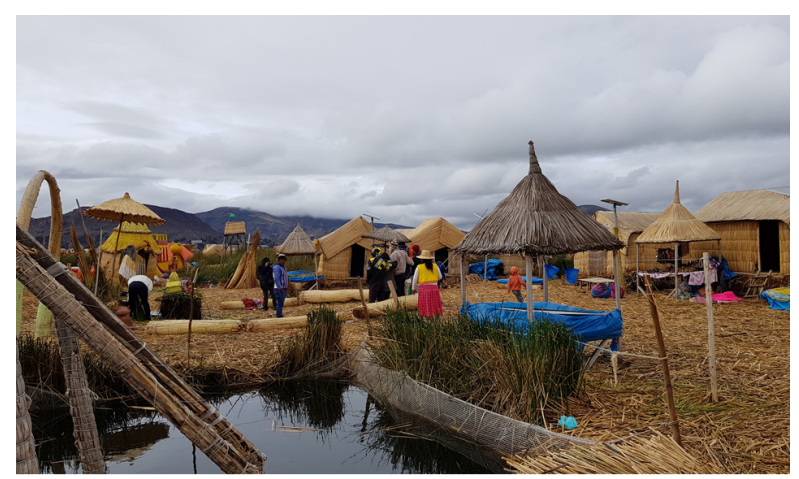

Figura 10. Islas flotantes de "Los Uros" en el Lago Titicaca, Puno. Ubicado a 3800 msnm. Arquitectura vernacular basada en el uso de la totora. Lastimosamente, más de la mitad de la población ya no habita en las islas que solamente son utilizadas como parte de la visita de turistas para lo cual se crea una puesta en escena simulada. Fuente: Fotografía del autor, 2017.

11. "Hoy por desgracia, la vida tradicional de los uros peruanos está en decadencia. Las visitas turísticas que reciben a diario desde Puno les han permitido mejorar sus ingresos, pero de los 3.000 que quedan en este lado peruano [...], más del $60 \%$ ha abandonado ya los hábitos ancestrales y viven tierra adentro o en islas cercanas a la costa donde reciben a los turistas y les venden sus artesanías, pero luego regresan a sus casas de ladrillo. Recuperado de: https://elpais.com/elpais/2014/09/11/ paco_nadal/1410448369_141044.html

\section{CONCLUSIONES}

El ámbito rural en el Perú, bajo las aseveraciones presentadas, se encuentra en una grave crisis que está conduciendo a la desaparición de sus modos tradicionales de convivencia, la cosmovisión, el cuidado del entorno ecológico, la conservación de un legado histórico y sus manifestaciones artísticas y culturales, entre ellas la expresada por su arquitectura vernacular; todas conformadoras de un número invalorable de identidades y del patrimonio natural y cultural del país. En ese sentido las condiciones que permiten una vuelta al entorno rural denominadas rururbana o nueva ruralidad como la industria turística, el crecimiento demográfico, la agroindustria y las actividades complementarias a estas deberían (re)evaluarse y ceñirse a una serie de protocolos y objetivos administrados y gestionados por las entidades públicas, locales y las instituciones académicas que, desde lo multidisciplinario, tengan por finalidad su rescate y conservación, revirtiendo el voraz proceso de modernización informal y neoliberal que permite la confluencia de los principales vicios y lastres de lo expresado en el ámbito popular urbano denominado "chicha" y el turismo de "colección" (Figura 11).

Es en este proceso informal y acultural, la arquitectura vernacular se ha visto reemplazada por nuevas tipologías, resultado directo de la serie de confluencias socioeconómicas que han señalado, más allá de un proceso de hibridación, uno de engullicion que, lastimosamente, es aceptado por un amplio sector de la sociedad como esperanza de modernización, sin entender la puesta en riesgo del legado histórico-cultural, como expresión espontánea, auténtica y apropiada en "una sacralización y veneración de esa otra modernidad" (López Soria en conversación personal, 2012).

Bajo estas condiciones, el actual proceso de la nueva ruralidad, dejado a la inacción institucional y el libre desarrollo irreflexivo social permite el libertinaje, donde cada individuo y grupo empresarial crea reglas propias y condiciones, en desmedro del bien común, apareciendo, de esta manera, una serie de tipologías arquitectónicas reflejadas en lo formal, espacial, funcional, constructivo y la imagen como resultado de lo ilegal, el individualismo, lo informal y la carencia de un acervo cultural que imposibilita, bajo estas condiciones, una categoría de hibridación entre lo "chicha" y lo vernacular (Figura 12). 
de la economía peruana, esta debe permitir estudios más profundos que puedan direccionar y establecer en los modelos socio-culturales expresiones artísticas y culturales importantes, verbigracia la música y la grafía chicha, como parte de una hibridación con la arquitectura vernácula. En este sentido, no es posible el actual estado de inacción hacia un proceso de influencia, hibridación y engullición de la arquitectura vernacular por parte de una arquitectura "chicha", mientras no se pueda demostrar que esta produce un bienestar social que decantará súbitamente hacia las diferentes categorías arquitectónicas, entre ellas las de hábitat, confort y la estética.

La arquitectura chicha [...] no se adapta al clima, ni a los materiales, ni a las culturas locales. Tampoco ha llegado a consolidar modelos y tipos característicos en cada lugar [...]. Puede superarse a partir de ser una arquitectura vernácula moderna, adaptada a su tiempo y a su lugar (Burga, 2010, p. 161).

Si se pretendiese realizar lo que Burga $(2013,2010)$ denomina una arquitectura vernácula moderna, esta deberá darse bajo un sentido auténtico que permita la apropiación, a través de un proceso espontáneo, pero vigilante de decantación. La incorporación de tecnologías que mejoren la calidad del hábitat, como las señaladas con los muros trombe en zonas de friaje y las investigaciones que permitan una mejora en la estructura asísmica como en el adobe, que en definitiva podrían alterar sus tipologías tradicionales, son condiciones surgidas de la necesidad y del bien común, permitiendo ser elemento simbólico que, en el tiempo se adapte y adopte en la memoria colectiva. En esa misma lógica, habrá que realizar un aprendizaje y desaprendizaje de lo cultural y artístico, como parte de una educación social que permita replantear o poner en juicio lo realizado en los espacios públicos como propuesta modista, banal y efímera, repensada desde las condiciones de autenticidad entre lo racional y simbólico, así como desde un entendimiento y reconocimiento de la belleza particular que adquiere el mundo rural, distinta y distante de consideraciones estéticas contemporáneas, dependientes de la hegemónica cultura occidental (Figura 13).

Finalmente, se hace necesario gestionar y promover lo que Leopoldo Zea señalaba como el espíritu crítico, es decir, el entendimiento de aquel espíritu que permitió a la población rural lograr un proceso de realización en la diversidad del espacio-tiempo y que se sitúa desde lo auténtico y apropiado. De esta manera, el espíritu crítico permitirá, en el modelo contemporáneo globalizado, anticipar, dilucidar y hacer frente a la sociedad del espectáculo y al turismo como "recurso", para la salvaguarda del patrimonio que debe pervivir desde y en el ámbito rural y la arquitectura vernácula, como una verdadera nueva ruralidad.

ESPÍRITU CRÍTICO : NUEVA RURALIDAD

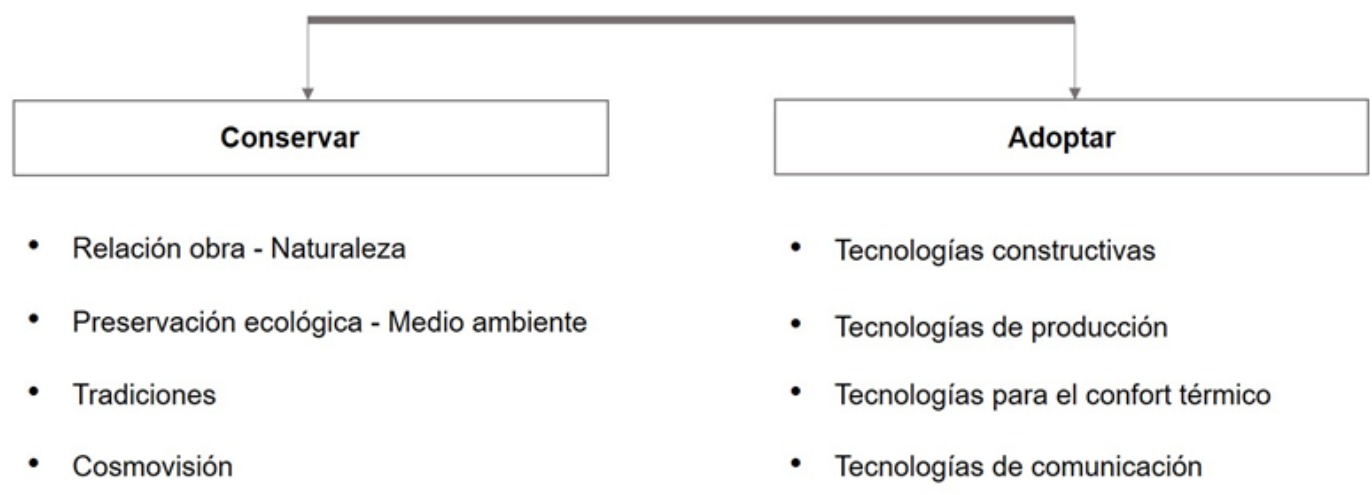

Figura 13. Condiciones para una Nueva Ruralidad Fuente: Elaboración propia. 


\section{REFERENCIAS}

Aguilar, P. (2012). ¿Rumbo a la modernidad? Sociedad y cultura como ejes de análisis antropológicos de la modernización neoliberal. Recuperado de: https://www.academia.edu/15460106/ Rumbo a la modernidad Sociedad y cultura como ejes de an\%C3\%A1lisis antrop\%C3\%B3logico de la modernizaci\%C3\%B3n neoliberal

Arango, G., (2008). Salvemos el espacio rur urbano colombiano. Cuadernos de Vivienda y Urbanismo. (2), 394-409.

Augé, M., (2000). Los "no lugares" espacios del anonimato. Una antropología de la sobremodernidad. Barcelona, España: Quinta reimpresión. Editorial Gedisa, S.A.

Barros, C. (2005). Identidades entre lo urbano y lo rural. X Encuentro de Geógrafos de América Latina, Sao Paulo, Brasil. Recuperado de: http://www.memoria.fahce.unlp.edu.ar/programas/pp.11147/pp.11147.pdf

Baumann, Z., (2013). Miedo Líquido. La sociedad contemporánea y sus temores. Segunda impresión. Espasa Libros, S.L.U.

Baumann, Z., (2012). Modernidad líquida. Buenos Aires, Argentina: Fondo de cultura económica.

Borja, K., (2016) Criar paisajes vivos, una manera de aprehender y (re) pensar la ciudad. Cuadernos de Vivienda y Urbanismo. 9 (18), 276-291.

Burga, J., (2013). Arquitectura popular. Una alternativa entre lo vernáculo y lo chicha. 50 años de arquitectura peruana. (pp. 100-115) Lima, Perú. K\&K Editores internacionales.

Burga, J., (2010). Arquitectura Vernácula peruana. Un análisis tipológico. Lima, Perú: Colegio de arquitectos del Perú.

Castañeda, C. (2012) "Entrevista a José López Soria". 17 de setiembre.

Castañeda, C. (2013). Memoria, Aceptación y Replanteo. Arquitextos. 20 (28), 23-35.

Castells, M., (2001). El poder de la identidad. Madrid, España: Versión castellana de Carmen Martínez. Alianza Editorial S.A.

Castells, M., (2000). La era de la información: economía, sociedad y cultura. La Sociedad Red. Segunda edición. Madrid, España: Edición Castellana Alianza Editorial, S.A.

Chion, M. (2002). Dimensión metropolitana de la globalización: Lima a fines del siglo XX. Eure. XXVIII. (85),7187.

Claverias, R. (2008). Desarrollo Territorial y Nueva Ruralidad en el Perú. Experiencias y Propuestas del CIED: 1990-2007. Lima, Perú: Centro de Investigación, Educación y Desarrollo.

Crosby, A., Ed. (2009) Re-inventando el turismo rural. Gestión y desarrollo. Barcelona, España: Laertes S.A.

Curtis, W. (2007). La arquitectura moderna desde 1900. Traducida del inglés por Jorge Sainz. Tercera edición en español (revisada, actualizada y ampliada) Reimpreso en 2007. Phaidon Press. Limited.

Degregori, C. (2000). Presentación. C. Degregori (Ed) No hay país más diverso. Compendio de antropología peruana (pp. 13-19). Lima, Perú: Red para el desarrollo de las Ciencias Sociales en el Perú. 
De Soto, H., (1986). El Otro Sendero. La revolución informal. Lima, Perú: Instituto Libertad y Democracia.

De la Mar, A. (2006). Identidades e identidad nacional en el mundo contemporáneo. Oasis. (11),19-37.

Dussel, E. (2005). Transmodernidad e Interculturalidad (interpretación desde la Filosofía de la Liberación) Recuperado de: http://afyl.org/transmodernidadeinterculturalidad.pdf

Frampton, K. (2000). Historia crítica de la arquitectura moderna. décima edición. Barcelona, España: Editorial Gustavo Gilli.

Franco, C. (2014) Exploraciones en "otra modernidad": de la migración a la plebe urbana. P. Sandoval y J.C. Agüero (Eds.). Cambios culturales en el Perú. (pp. 12-53) Cusco, Perú: Ministerio de Cultura/ Dirección Desconcentrada de Cultura de Cusco. Subdirección de Interculturalidad. Fondo Editorial.

Franco, C., (1991). Imágenes de la sociedad peruana: la otra modernidad. Lima, Perú: CEDEP.

Gaudin, Y. (2019) Nuevas narrativas para una transformación rural en América Latina y el Caribe. La nueva ruralidad: conceptos y medición. Ciudad de México. México: Ediciones Naciones Unidas.

Giménez, G., (2007). Estudio sobre la cultura y las identidades sociales. México. Consejo Nacional para la Cultura y las Artes.

Gonzales de Olarte, E. y Samamé, L., (1991). El péndulo peruano. Políticas económicas, gobernabilidad y subdesarrollo 1963-1990. Lima, Perú: Instituto de estudios peruanos ediciones.

Grimson, A., (2011). Los límites de la cultura. Critica de las teorías de la identidad. Buenos Aires, Argentina: Siglo Veintiuno editores argentina, S.A.

Gutiérrez, R., (1997). Arquitectura Latinoamericana. Textos para la reflexión y la polémica. Lima, Perú: Epígrafe Editores S.A.

Hall, S. (2007) Lo local y lo global. Globalización y etnicidad. Recuperado de: https://centroderecursos. cultura.pe/sites/default/files/rb/pdf/Lo-local-y-lo-global.pdf

Ivars, J. (2000). Turismo y espacios rurales: conceptos, filosofías y realidades. Revistas Investigaciones Geográficas (23).59-88.

Kymlicka, W. (1996). Ciudadanía multicultural. Una teoría liberal de los derechos de las minorías. Traducción de: Carme Castells. Barcelona, España. Editorial Paidós.

Larraín, J., (2017). Identidad chilena. Segunda edición actualizada. Santiago, Chile: LOM ediciones.

Larraín, J. (2005). ¿América Latina moderna? Globalización e identidad. Santiago, Chile: LOM ediciones.

Lipovetsky, G. y Charles, S., (2008). Los tiempos hipermodernos. Traducción de Antonio-Prometeo Moya. Segunda edición. Barcelona, España: Editorial Anagrama.

López Soria, J. (2007). Adiós al discurso moderno en el Perú. Recuperado de: https://sites.google.com/site/ jilopezsoria/escritos

López Soria, J. (2001) Adiós al discurso Moderno, Hueso Húmero. (39), 47-57.

Ludeña, W. (2013). Espacios Públicos, Arte Urbano y Diseño. La otra ciudad peruana. En: Espacio público, arte y ciudad. Primera edición. (pp. 155-187) Lima, Perú: Pontificia Universidad Católica del Perú.

Ludeña, W. (2006). Ornato público y corrupción estética. Gaceta cultural del Perú, (22), 12-13. 
Marina, J., (2000). Crónicas de la ultramodernidad. Barcelona, España: Editorial Anagrama.

Matos, J., (1984). Desborde Popular y crisis del Estado. El nuevo rostro del Perú en la década de 1980. Lima, Perú: Instituto de Estudios Peruanos. IEP ediciones.

Ministerio de Comercio Exterior y Turismo, (2016). Pentur. Plan Estratégico Nacional de Turismo 2025. Lima, Perú: Biblioteca Nacional del Perú.

Ministerio de Desarrollo e Inclusión Social (2017). Evaluación de Impacto de la primera fase de "Mi Abrigo". Línea de base. Lima, Perú: Biblioteca Nacional del Perú.

Ministerio de Vivienda, Construcción y Saneamiento (2009). Estudio de reconstrucción con viviendas sismoresistentes en la República del Perú. Informe final. Lima, Perú: Biblioteca Nacional del Perú.

Palau, M., (2002). Introducción a la semiótica de la arquitectura. San Luis de Potosí, México: Editorial Universitaria Potosina.

Perniola, M. (2016) La estética contemporánea. Traducción de Francisco Campillo. Madrid, España: Editorial A. Machado Libros, S.A.

Perniola, M. (2001) La estética del siglo XX. Madrid, España: Editorial A. Machado Libros, S.A

Plaza, O. (1998). Desarrollo Rural: Enfoques y métodos alternativos. Lima, Perú. PUCP Fondo Editorial.

Ramírez, J., (2013) Las huellas que revelan el tiempo (1985-2011) Seminarios de Arquitectura Latinoamericana$S A L$. Bogotá, Colombia: Editorial Universidad Nacional de Colombia.

Rodríguez, R., (2004). Transmodernidad. Barcelona, España: Editorial Anthropos.2004.

Sassen, S. (2007) Una sociología de la globalización. Traducción de: Rodil, María. Buenos Aires, Argentina: Katz editores.

Sobrevilla, D. (1973). La cultura y la filosofía de la dominación. Apuntes sobre un planteo de Augusto Salazar Bondy. Apuntes: Revista de Ciencias Sociales, (1),49-66.

Subercaseaux, B. (2006). Identidad y Destino: El caso de Chile. G. Rozas y J. Arredondo (Comp.), Identidad, Comunidad y Desarrollo. (pp. 19-36). Santiago, Chile: Facultad de Ciencias Sociales. Universidad de Chile. Gráfica LOM.

Taylor, C. (1993). El multiculturalismo y la "política del reconocimiento". Recuperado de: http://red.pucp.edu. pe/wpcontent/uploads/biblioteca/elmulticulturalismoylapoliticadelreconocimientocharlestaylor.pdf

Tokeshi, J. (2004) Para pensar la ciudad del siglo XXI. La ciudad popular peruana hoy: 6 tesis. Documentos de arquitectura y urbanismo. DAU. (5), 94-111.

Tokeshi, J. (1999) Suelo y cielo de la ciudad popular. Arquitextos, 6 (10), 75-84.

Touraine, A. (1997). Diferencias culturales y ciudadanía. En: J. Gonzales (Ed.), Ciudadanía y cultura. (pp.291305) Bogotá, Colombia: Universidad Nacional de Colombia. Tercer Mundo Editores.

Urry, J. y Larsen, J., (2014). La mirada del turista, turismo y sociedad. Segunda edición en español. Lima, Perú: Editorial de la Universidad de San Martin de Porres.

Vargas Llosa, M. (2012). La civilización del espectáculo. Lima, Perú: Santillana Ediciones Generales, S.L.

Vattimo, G., (1996) La sociedad transparente. Segunda reimpresión. Traducción de Oñate, Teresa. Barcelona, España: Ediciones Paidós Ibérica S.A. 
Villoro, L. (2001). La búsqueda de la identidad en la cultura latinoamericana. Devenires (2) 132-146.

Waisman, M., (1993). El interior de la historia. Historiografía arquitectónica para uso de latinoamericanos. Segunda edición. Colombia: Escala editorial.

Yúdice, G., (2002). El recurso de la cultura. Usos de la cultura en la era global. Traducción de: Gabriela Ventureira, excepto capítulo 7: Desiderio Navarro. Primera edición. Barcelona, España.

Zea, L. (1974). Dependencia y liberación en la cultura latinoamericana. Primera edición. México: Editorial Cuadernos de Joaquín Mortiz. 